Nubia Correia do Rego

Longevidade e retenção de pessoas nas empresas

Great Place to Work (GPTW)

Dissertação apresentada ao Programa de Pósgraduação em Administração de Empresas da PUCRio como requisito parcial para obtenção do título de Mestre em Administração de Empresas.

Orientadora: Profa. Patrícia Amélia Tomei

Rio de Janeiro

Fevereiro 2014 
Nubia Correia do Rego

\section{Longevidade e retenção de pessoas nas empresas Great Place to Work (GPTW)}

Dissertação apresentada como requisito parcial para obtenção do grau de Mestre pelo Programa de PósGraduação em Administração de Empresas da PUC-Rio. Aprovada pela Comissão Examinadora abaixo assinada.

Prof ${ }^{a}$. Patricia Amelia Tomei

Orientadora

Departamento de Administração - PUC-Rio

Profa. Ana Heloísa da Costa Lemos Departamento de Administração - PUC-Rio

Prof. Giuseppe Maria Russo Dedix Assessoria Técnico-Científica Ltda.

Profa. Mônica Herz Vice-Decana de Pós-Graduação do CCS - PUC-Rio

Rio de Janeiro, 24 de fevereiro de 2014 
Todos os direitos reservados. É proibida a reprodução total ou parcial do trabalho sem autorização da universidade, da autora e da orientadora.

\section{Núbia Correia do Rêgo}

Possui experiência de mais de 30 anos em Gerenciamento de Projetos, atuando em Tecnologia da Informação e Automação Industrial, em várias companhias de grande porte. Atualmente é Diretora Executiva na Ernst \& Young na área de Assessoria Empresarial e Sócia-fundadora da Inspirartis, empresa que presta serviços de coaching vocacional e de carreira para jovens. É coautora do livro "Capacitação em Gerenciamento de Projetos - Guia de Trabalho", com dedicação exclusiva no desenvolvimento do conteúdo de Gerenciamento de Mudanças: capacitação, comunicação e alinhamento organizacional. Palestrante atuante na área de Projetos. Possui Certificação em Gerenciamento de Projetos pela Stanford University (SCPM), com MBA Executivo Internacional em Gerenciamento de Projetos pela FGV e UCI, Pósgraduação em Análise de Sistemas, é Contadora e Estatística. Professora convidada em cursos de PósGraduação "Lato-sensu" para Fundação Getulio Vargas, Universidade Cândido Mendes, Universidade Gama Filho, Universidade Estácio de Sá, em seus cursos de PósGraduação em Gerenciamento de Projetos.

Ficha Catalográfica

Rego, Nubia Correia do

Longevidade e retenção de pessoas nas empresas Great Place to Work (GPTW) / Nubia Correia do Rego ; orientadora: Patrícia Amélia Tomei. - 2014.

161 f. : il. (color.) ; $30 \mathrm{~cm}$

Dissertação (mestrado)-Pontifícia Universidade Católica do Rio de Janeiro, Departamento de Administração, 2014.

Inclui bibliografia

1. Administração - Teses. 2. Empresas longevas. 3. Longevidade organizacional. 4. Melhores empresas para trabalhar. 5. Maiores empresas. 6. Retenção de pessoas. I. Tomei, Patrícia Amélia. II. Pontifícia Universidade Católica do Rio de Janeiro. Departamento de Administração. III. Título. 
Aos meus filhos David, Levy e Gabi, que trazem um significado especial para a minha vida. 


\section{Agradecimentos}

Em primeiro lugar agradeço ao meu espírito, centelha Divina que age e habita em mim, que me move em todas as minhas ações. Estou aqui hoje por que ele me sustenta, não me deixando fraquejar, nem desistir.

Agradeço ao Ser Superior que me orienta, ampara e ilumina meus caminhos, a quem eu chamo de Deus.

Aos meus filhos David, Levy e Gabi (Gabriela), seres de luz que recebi de presente para educar e criar. Obrigada pela paciência de me ver sem tempo, chegando tarde, dedicando minhas noites para essa meta. Sem a compreensão de vocês, sem o incentivo e torcida, eu teria desistido. Esse título eu dedico a vocês!

Aos meus pais que sempre acreditaram em mim e me incentivaram nas minhas lutas e comemoraram comigo as minhas conquistas. Mãe, onde quer que você esteja...

Ao meu irmão Geovani, a quem sou unida por laços de sangue e amizade, nosso vínculo me impulsiona e me move. 
À minha cunhada Luciana, meus sobrinhos amados Gabriel e Mariana, por todo o amor e apoio que nos une.

Á minha irmã Alliny, amiga Fátima, cunhado Marcos, valeu por cada palavra de incentivo.

À minha irmã de vida Marry (Mariângela), pela sua paciência com minha ausência durante esse tempo. O que nos une é forte e inabalável.

Aos meus irmãos e sócios da Inspirartis e "luizes” da minha vida, Luiz Mendes e LEC (Luis Costa), por me entenderem na ausência e estarem comigo em todas as lutas.

A Girlsonthe Books (Rafa, Luna, Iria, Luiza, Bia, Carol e Fê), pela cumplicidade que construímos, pelo apoio, pelo carinho... esses dois anos serão inesquecíveis, vocês são inesquecíveis.

Ao Carlos Assis, Tadeu, Carlos Storino e Paulo, por todo o suporte no trabalho para que eu pudesse estar no Rio para estudar, sair para aula, concluir dissertação... vocês foram incríveis!

À Cândida, Teresa, Camila e Adriana, por todo o suporte na finalização e impressão de meus trabalhos.

A minha orientadora, mestre e amiga, Patrícia Tomei (Pat), pela bronca inicial, pela paciência, pela rapidez nas respostas, pela altíssima competência, pelo grande conhecimento compartilhado... Sem a sua orientação eu me perderia totalmente.

Aos meus professores, por todo o ensinamento passado, por toda experiência compartilhada.

Aos Professores Doutores Giuseppe Maria Russo, Ana Heloísa da Costa Lemos e Flávia de Souza Costa Neves Cavazotte por participarem da Comissão Julgadora deste trabalho e contribuírem para o fechamento deste ciclo em minha vida.

Ao Fábio e Teresa, pela paciência e suporte aos meus pedidos, cada vez que eu perturbava na Secretaria.

Ao amigo Ruy Shiozawa, Presidente da GPTW Brasil, que meu apoiou nesse desafio e permitiu que esse sonho se realizasse. Sem o suporte da GPTW ao longo de toda a pesquisa e de toda equipe competente ali presente, eu não teria chegado até aqui. Meu eterno agradecimento.

Ao Nelson Emiliano, Marcelo Estácio e Rose Vieira, pelo suporte com a estatística.

Aos meus amigos, a quem deixei de lado e disse tanto "não posso ir" durante esse tempo, pelas palavras de incentivo ao longo desse período, obrigada por continuarem ao meu lado. 


\section{Resumo}

Rego, Nubia Correia do; Tomei, Patricia Amélia Tomei. Longevidade e retenção de pessoas nas empresas Great Place to Work(GPTW). Rio de Janeiro, 2014. 161p Dissertação de Mestrado - Departamento de Administração, Pontifícia Universidade Católica do Rio de Janeiro.

Este trabalho analisou a relação entre as melhores empresas para trabalhar, a retenção de pessoas e a longevidade organizacional, isto é, se as empresas mais longevas são as melhores empresas para trabalhar e que mais apresentam características de atração e retenção de seus profissionais. Foi realizada uma pesquisa exploratória, explicativa e descritiva com base em dados secundários do ranking Great Place to Work (GPTW) brasileiro de 2013. A abordagem quantitativa focou um universo de 327 empresas nacionais, do qual foi identificada uma amostra de 70 grandes empresas premiadas no ranking, subdivididas em três grupos: as empresas mais jovens (EMJ), que são empresas de 3até 34 anos de idade; empresas mais velhas (EMV), que são empresas entre 35 e 49 anos de idade; empresas muito mais velhas (EMMV), que são empresas com mais de 50 anos de idade. Conclui-se que a relação entre longevidade e práticas comportamentais de atração e retenção de pessoas não foi confirmada neste estudo, uma vez que pudemos identificar que existem fatores de desenvolvimento de pessoal que também interferem na retenção de pessoas em um numero significativo de empresas não longevas. Portanto, concluímos neste trabalho que não são apenas as empresas longevas que praticam políticas de atração e retenção de pessoas. Por fim, a partir da análise das variáveis comportamentais, identificamos que a liderança é fator relevante nas práticas adotadas e propomos para uma pesquisa futura, uma investigação especifica do papel do líder na retenção de pessoas e longevidade empresarial.

\section{Palavras-chave}

Empresas longevas; longevidade organizacional; melhores empresas para trabalhar; maiores empresas; retenção de pessoas. 


\section{Abstract}

Rego, Nubia Correia do; Tomei, Patricia Amélia Tomei (Advisor). Longevity and employee retention in companies Great Place to Work (GPTW). Rio de Janeiro, 2014. 161p. MSc. Dissertation - Departamento de Administração, Pontifícia Universidade Católica do Rio de Janeiro.

This study analyzed the relationship among great place to work companies and organizational longevity and employee retention, it means, if the longer-lived companies are the best companies to work for and if they practice more initiatives that can influence employee attraction and retention. That is an exploratory, explanatory and descriptive research based on secondary data from Great Place to Work (GPTW) 2013 Brazilian Ranking. The quantitative approach is used and that is focused on an universe of 327 domestic companies, from which was identified a group of 70 large companies awarded in the referenced raking, and it was subdivided into three groups: younger companies (EMJ), companies that are between 3 and 34 years old; older companies (EMV), companies that are between 35 and 49 years old, the oldest companies (EMMV), which are companies with over 50 years of age. We concluded that the relationship between longevity and behavioral practices for attracting and retaining employees was not confirmed in this study, since we could identify that there are some practices and factors that influence the retention of talent in a significant number of younger companies. Therefore, we conclude this study that there are not only long-lived companies that practice policies for attracting and retaining talent. Finally, from the analysis of behavioral variables it was identified that leadership is a relevant factor in practices and we suggest for future research, an investigation of the specific role of the leader in employee retention and business longevity.

\section{Keywords}

Long-lived companies; organizational longevity; great place to work; greatest companies; employee retention. 


\section{Sumário}

1. Introdução 15

1.1. Objetivos do Trabalho 18

1.2. Relevância do Estudo 19

1.3. Delimitação do Escopo do Estudo 21

1.4. Estruturação da Dissertação 21

2. Referencial Teórico 23

2.1. Longevidade 23

2.1.1. Longevidade Organizacional 23

2.1.2. Organizações Longevas 24

2.1.3. Longevidade Organizacional e Pessoas $\quad 27$

2.1.4. Resumo do Estudo Sobre Longevidade Muda este Titulo para Pesquisas Recentes em Longevidade Organizacional 28

2.2. Retenção de Pessoas 31

2.2.1. Atração e Retenção de Pessoas sob a Ótica
PELOSO (2010)

2.2.2. Estratégia de Retenção Através da Satisfação das Pessoas, Uma Ótica de GERING e CONNER (2002) 34

2.2.3. Fatores Organizacionais que Influenciam na Retenção de Pessoas, sob a Ótica de PINTO (2008) 36

2.2.4. Fatores Organizacionais que Influenciam na Retenção de Pessoas, sob a Ótica de HOISCH (2001) 38

2.3. Melhores Empresas para Trabalhar e Desempenho 39

2.3.1. Melhores Resultados para os Acionistas - Estudos de

CARDOSO DA SILVA (2009) / LIMA e CORRAR (CORRAR), para Empresas Brasileiras

2.3.2. Pesquisa de Alex Edmans, pela Wharton University of Pennsylvania

2.3.3. Análise Retorno para os Acionistas das Melhores Empresas para Trabalhar, por Situs Consultoria em 2012.

2.4. Great Place to Work (GPTW®)

2.4.1. Sobre a Great Place to Work (GPTW®)

2.4.2. Metodologia da Pesquisa GPTW®

2.4.2.1. Ciclo de Apuração e Fechamento Lista das Melhores

2.4.2.2. Processo de Atribuição de Notas e Ranqueamento

2.4.2.3. Visão GPTW® de um Excelente Lugar para Trabalhar

2.4.2.4. Diferencial do Great Place to Work

3. Metodologia

3.1. Tipo de Pesquisa 53

3.1.1. Classificação Segundo sua Finalidade 54

3.1.2. Classificação Segundo seus Objetivos mais Gerais 54

3.1.3. Classificação Segundo seus Métodos Empregados 55

3.1.4. Classificação Quanto aos Meios 55

3.1.4.1. Abordagem Quantitativa $\quad 55$

3.2. Universo e Amostra 56

3.3. Coleta dos Dados 57 
3.4. Tratamento dos Dados 57

3.4.1. Tabulação de Longevidade $\quad 57$

3.4.2. Idade de Empresas Longevas 60

3.4.3. Tabulação de Retenção de Pessoas 60

3.4.4. Associação dos Temas de Retenção de Pessoas com as Práticas GPTW ${ }^{\circledR} \quad 62$

3.4.5. Tabulação de Longevidade e Retenção de Pessoas 65

3.4.6. Dados Qualitativos e Software Utilizado 66

3.4.7. Metodologia Estatística e Software Utilizado 66

3.5. Questões da Pesquisa $\quad 67$

3.6. Limitações do Método 67

4. Descrição e Análise dos Resultados 68

4.1. Introdução 68

4.2. Descrição dos Dados 69

4.2.1. Confiabilidade do Questionário 69

4.2.2. Análise Descritiva da Base de Dados com 70 Empresas

4. 69

$\begin{array}{ll}\text { Premiadas e não Premiadas } & 75\end{array}$

4.3. Análise dos Dados 85

4.3.1. Considerações Gerais Acerca das 70 Grandes e
Multinacionais Premiadas

4.3.2. Considerações Gerais Acerca da Base Completa, Empresas

Premiadas e não Premiadas $\quad 88$

5. Conclusão 93

5.1. Limitações e Sugestões para Pesquisas Futuras 95

6. Referencias Bibliográficas 96

Anexos $\quad 100$

Anexo I - Pesquisa GPTW 2013 - Com Funcionários 100

Anexo II - Pesquisa GPTW 2013 - Com a Empresa 104

Anexo III - Pesquisa GPTW 2013 - Critérios de Avaliação Culture

Audit ${ }^{\circledR} \quad 111$

Anexo IV - Pesquisa GPTW $®$ - Correlação Perguntas do
Questionário com a base de Dados

Anexo V - Pesquisa GPTW 2013 - Análise e Resultados $\quad 114$

Anexo VI - Resultados Estatísticos $\quad 116$ 


\section{Lista de figuras}

Figura 1: Análise retorno para acionista 42

Figura 2: Dimensões GPTW 45

Figura 3: Abordagem metodológica GPTW 49

Figura 4: Visão melhor empresa para trabalhar GPTW 51

Figura 5: Processo 9 to 5 GPTW 52

Figura 6: Etapas para desenvolvimento de pesquisa 53

Figura 7: Pesquisa GTPW 2013, resultados 114

Figura 8: CEOs na função 115

Figura 9: Serviços prestados GPTW 115 


\section{Lista de tabelas}

Tabela 1: Amostragem mínima de respondentes 46

Tabela 2: Informações gerais e características de atração e retenção das 70 grandes e multinacionais premiadas

Tabela 3: Correlação do faturamento com as características de atração e retenção de profissionais (70 grandes e multinacionais premiadas)

Tabela 4: Correlação da quantidade de trabalhadores com as características de atração e retenção de profissionais ( 70 grandes e multinacionais premiadas)

Tabela 5: Setor de atuação VS características de atração e retenção (70 grandes e multinacionais premiadas)

Tabela 6: Idade das empresas (70 grandes e multinacionais premiadas)

Tabela 7: idade das empresas VS características de retenção e atração de profissionais (70 grandes e multinacionais premiadas) Tabela 8: correlação da idade com as características de atração e retenção de profissionais (70 grandes e multinacionais premiadas)

Tabela 9: modelos de regressão para as cinco dimensões do questionário

Tabela 10: modelos de regressão para o número de respondentes

Tabela 11: Idade das empresas (70 grandes e multinacionais premiadas)

Tabela 12: Idade das empresas (70 grandes e multinacionais premiadas)

Tabela 13: correlação da idade com as 58 questões que compõem o questionário (70 grandes e multinacionais premiadas)

Tabela 14: estatísticas das questões por dimensão para todas as 327 empresas participantes

Tabela 15: estatísticas das questões por tema para todas as 327 empresas participantes

Tabela 16: modelos de regressão para as nove práticas

Tabela 17: modelos de regressão para os quatorze temas 


\section{Lista de quadros}

Quadro 1: Ações específicas de desenvolvimento gerencial

Quadro 2: Principais estudos sobre o tema da longevidade organizacional

Quadro 3: Semelhanças nas praticas de gestão

Quadro 4: Tabulação de Longevidade

Quadro 5:Tabulação de Retenção de Pessoas

Quadro 6: Associação da Tabulação de Retenção de Pessoas com as 9 Práticas GPTW

Quadro 7: Tabulação de Longevidade e Retenção de Pessoas com as 9 Práticas GPTW

Quadro 8: Resumo dos resultados encontrados - análise teorias

Retenção de Pessoas e Longevidade

Quadro 9: Conclusão, resultado análise das hipóteses de questão da pesquisa 


\section{Lista de gráficos}

Gráfico 1: distribuição da idade (70 grandes e multinacionais premiadas)

Gráfico 2: distribuição do faturamento (70 grandes e multinacionais premiadas)

Gráfico 3: distribuição do setor de atuação (70 grandes e multinacionais premiadas)

Gráfico 4: idade média por setor de atuação (70 grandes e multinacionais premiadas) 